\title{
Factors Contributing Toward Men's Engagement With HIV Services: A Narrative Review
}

\author{
Tafadzwa Dzinamarira ${ }^{1} \&$ Tivani Phosa Mashamba-Thompson ${ }^{1,2}$ \\ ${ }^{1}$ Department of Public Health Medicine, School of Nursing and Public Health, University of KwaZulu-Natal, \\ Durban, South Africa \\ ${ }^{2}$ CIHR Canadian HIV Trials Network, Vancouver BC, Canada \\ Correspondence: Tafadzwa Dzinamarira, Department of Public Health Medicine, School of Nursing and Public \\ Health, University of KwaZulu-Natal, Durban, 4001, South Africa. Tel: 250-786-999-838. E-mail: \\ 219095120@stu.ukzn.ac.za; anthonydzina@gmail.com
}

Received: July 11, 2019 Accepted: August 14, 2019 Online Published: August 22, 2019

doi:10.5539/gjhs.v11n10p150 URL: https://doi.org/10.5539/gjhs.v11n10p150

\section{Summary}

Men lag behind women in regard to uptake of HIV services. In this paper, the authors review factors that affect men's engagement in HIV services and explore the potential of HIV self-testing to bridge this gap. This paper concludes with a proposed framework that will help to improve the engagement of men with HIV services.

\begin{abstract}
Within low- and middle-income countries, Human Immunodeficiency Virus (HIV) falls among the main causes of adult morbidity and mortality. In order to achieve epidemic control, targeted testing with the aim of identifying those unaware of their infection with HIV remains the first step in a series of efforts that include constant extension of HIV treatment programs, as well as other prevention interventions. HIV self-testing (HIVST) is a new intervention that is capable of increasing the uptake of HIV-testing services (HTS) within traditionally hard-to-reach populations, such as men. We sought to review the literature on factors contributing to male aversion of HTS, health education for men and their engagement in health services, and the rate of HIVST acceptability among men. We reveal poor health-seeking behavior as the underlying factor contributing to poor uptake of HTS by men. Furthermore, our review reveals that health education programs have been recommended to address poor health-seeking behavior and improve HTS uptake among men. Studies reported high acceptability of HIVST among men. We conclude by proposing a framework to help improve men's engagement in health services in general.
\end{abstract}

Keywords: HIV, HIV self-testing, men

\section{Introduction}

Human Immunodeficiency Virus (HIV) currently remains a leading cause of adult morbidity and mortality in lowand middle-income countries (LMICs) (UNAIDS, 2017b). Worldwide, different interventions have led to most countries nearing epidemic control, with a key emphasis on knowing one's HIV status, however, available evidence shows a low utilization rate of HIV-testing services among men (Kojima \& Klausner, 2018; UNAIDS, 2014, 2017a, 2017b). Targeted testing aimed at identifying individuals who were not aware of their HIV infection status (the first 90 target), as well as the continuous expansion of HIV treatment programs and other preventative interventions required for the facilitation of ultimate epidemic control (Justman et al., 2017).

In response, The World Health Organization (WHO) published the first global guidelines on HIV self-testing (HIVST) in 2016 (WHO, 2016). This intervention is capable of significantly increasing uptake of HIV-testing services (HTS) among the hard-to-reach populations. Studies from settings where HIVST has been piloted showed high acceptability among men (Choko et al., 2015; Gichangi et al., 2016; Lippman et al., 2018; Masters et al., 2016). However, dedicated strategies based on research must be developed and used in this generally hard-to-reach population (Justman et al., 2017).

Male aversion of HTS has been linked to poor health-seeking behavior (Skovdal et al., 2011). Historically, health education programs (HEPs) have been reported to build individuals' skills, knowledge, and positive attitudes concerning health (Hubley, 1980; Kumar \& Preetha, 2012). In tandem, HEPs have been recommended to address 
poor health-seeking behavior among key populations, including men, and improve uptake of HTS (Conserve et al., 2018; Vanessa, 2013). This study mainly aims to review the existing literature on factors contributing toward men's engagement with HIV services, focusing on the challenges linked to men's engagement with health services and associated factors, acceptability of HIV self-testing interventions by men, and HEPs aiming to improve men's engagement in healthcare services. Based on the reviewed literature, we recommend a framework which aims to improve the level of engagement of men with health services in LMICs. We searched PubMed, the Cochrane Database of Systematic Reviews, EBSCOhost (CINAHL and Academic Search Complete), Web of Science, WHO library, and Google Scholar, and used the search terms "health", "education", "program", "men", "men engagement", and "HIV testing services" to find relevant literature for this review.

\section{Health Seeking Behavior of Men}

Health-seeking behavior (HSB) refers to a dynamic process which generally progresses through several phases, including self-assessment of symptoms, self-treatment, seeking professional advice, and follow-up of any given professional advice (Gerald \& Ogwuche, 2014). Health-seeking behavior is any kind of action that individuals who regard themselves to be ill undertake to ensure that they receive correct treatment (Olenja, 2003). Available evidence shows women generally seek health services more often than men (Gerald \& Ogwuche, 2014; Olenja, 2003). Poor health-seeking behavior among men manifests in delayed help and treatment, culminating in increased morbidity and mortality (Galdas, Cheater, \& Marshall, 2005; Kakkar, Kandpal, Negi, \& Kumar, 2013; Olenja, 2003). Some issues leading to this phenomenon that have been reported include individuals' knowledge and perceptions, sociocultural factors, and economic factors (Kakkar et al., 2013). HSB is affected by an individual's perceived susceptibility to disease, the level of severity of the given disease, the perceived effectiveness of the preventative behavior, and cost, which are all associated with preventative behavior (Galdas et al., 2005).

HSB may be influenced by values and beliefs of the community (Gerald \& Ogwuche, 2014). Further, attitudes of healthcare providers also affect decisions regarding whether to seek healthcare (Gerald \& Ogwuche, 2014). Healthcare providers have been reported to be more welcoming to women in comparison to men (Galdas et al., 2005; Gerald \& Ogwuche, 2014). A population-based cross-sectional study in Ethiopia demonstrated that, in general, men with a cough for at least two weeks were reluctant to seek healthcare services (Senbeto, Tadesse, Tadesse, \& Melesse, 2013). Similar findings were reported in Nigeria (Biya et al., 2014). A lack of sufficient knowledge regarding tuberculosis was the main reason contributing to delay in patients seeking healthcare (Biya et al., 2014); scholars have recommended intensifying health education programs to improve HSB (Biya et al., 2014; Senbeto et al., 2013). The most important descriptive factor influencing HSB was found to be the characteristics of the healthcare service itself (Adegoke, 2010). In rural settings, availability of money at the time of illness, religious background, age, educational background, and severity of the sickness were reported as factors (Omotoso, 2010).

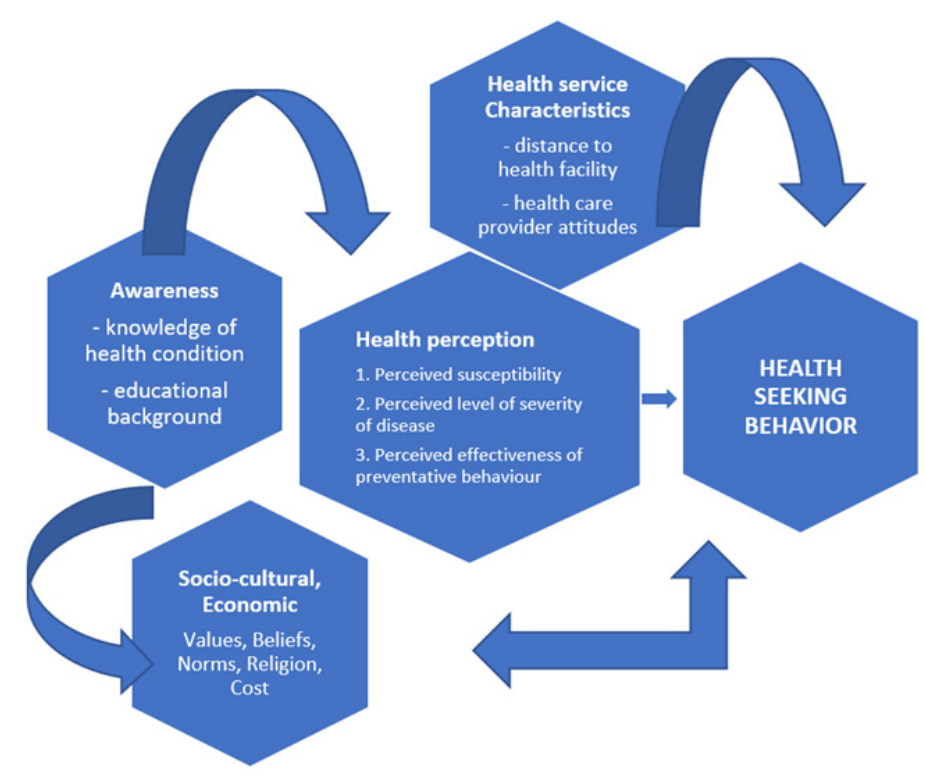

Figure 1. Diagrammatic representation of the factors influencing health-seeking behaviour (Dzinamarira $\mathrm{T}$ and Thompson-Mashamba T.P, 2019) Regina E. Ella 
Figure 1 demonstrates factors that have been shown to influence HSB. The following section discusses further studies that illustrated the influence that HSB has on men's engagement with healthcare services.

\section{Challenges Relating to Men's Engagement With Health Services in LMICs}

Factors contributing to poor health-seeking behavior can be categorized into sociocultural and biological factors (Smith, Braunack-Mayer, \& Wittert, 2006). Sociocultural factors refer to socially determined stereotypes, in which men are required to be "manly" or masculine to be socially accepted. They refer to the cultural and traditional masculine identities, which have been constructed by societies over time (Smith et al., 2006). Physical accessibility of given healthcare facilities, education, income level, and religious beliefs have also been revealed as factors (Smith et al., 2006). In the same light, Nzama notes that service providers can also affect men's health-seeking behavior (Nzama, 2013). The scholar further argues that, based on societal views and differences in gender stereotypes, healthcare workers are generally more prone to show compassion toward women seeking healthcare in comparison to men (Nzama, 2013). In addition, men tend to perceive that they indirectly access healthcare through their partners. Consequently, men often take their partners' HIV test results to reflect their own, known as HIV by proxy testing (Nzama, 2013).

Political factors have also been identified as barriers to men seeking healthcare (Shaikh \& Hatcher, 2004). In Pakistan, similar factors, including political, physical, socio-economic, and cultural factors, were reported (Shaikh \& Hatcher, 2004). In Uganda, Musoke et al. conducted a similar study, revealing that although $89 \%$ of participants, who were mainly women, were fully aware of the existence of mobile clinics in the community, just $28 \%$ had obtained such services within the previous month (Musoke, Boynton, Butler, \& Musoke, 2014). The findings also indicated that a large, mostly male, proportion of participants (84\%), were not aware of the existence of community health workers in their communities (Musoke et al., 2014). The study noted that HSB of participants relating to the last time they were sick was linked to age $(p=0.028)$, as well as their occupation $(p=0.009)$. The conclusions of the study discussed the huge potential regarding increasing access to healthcare within rural regions through increasing the number of mobile clinic services and bolstering community health worker strategies.

Nzama also carried out research in South Africa, noting that HSB in men is imperative as it offers the opportunity of gaining proper comprehension of men's health and the manner in which masculinity results in the underutilization of healthcare services (Nzama, 2013). The findings of the research also point out that essential health-related behaviors are generally influenced by dominant masculine personalities, which develop as a consequence of societal attitudes and which generally encourage behaviors such as binge drinking, drug use, and unprotected sexual activities with multiple concurrent sexual partners; these behaviors significantly affect the overall health of these men. Additionally, the findings of this research reveal masculinity issues having an impact on healthcare (Nzama, 2013).

\section{Challenges Related to Men'S Engagement With Health Services in High-Income Countries}

A study conducted in the US reported that men are generally less likely compared to women to obtain assistance from health professionals for challenges like substance abuse, depression, stressful life events, and physical disabilities (Galdas et al., 2005). This is in line with studies which have been carried out in LMICs (Adegoke, 2010; Biya et al., 2014; Senbeto et al., 2013). Similar findings have been reported in the United Kingdom (Sullivan, Camic, \& Brown, 2015). These studies indicate that "traditional masculine behavior" commonly observed in men can explain the delay in seeking help among men who experience different kinds of illnesses (Galdas et al., 2005; Sullivan et al., 2015). In this regard, scholars have argued that both emotional and interpersonal development in men together with male gender role socialization can influence men's attitudes when it comes to seeking psychological assistance (Sullivan et al., 2015).

In Canada, Thompson et al. used a Responsive Care Scale to reflect the level of healthcare-seeking behavior across 11 health conditions. In their study, patients' self-reports revealed that there were generally gender differences in HSB (Thompson et al., 2016). The findings of the study indicated that women visited their primary care provider more often than men for mental and physical health concerns (Thompson et al., 2016). For both men and women, the findings based on the regression analysis showed that illness prevention, age, trust in the physician, and chronic conditions were highly significant factors when it came to healthcare-seeking behaviors for mental health concerns (Thompson et al., 2016). This research has various implications for people working to improve barriers to healthcare access through the identification of those who are highly likely to engage in healthcare-seeking behaviors.

According to Smith et al., help-seeking behavior of men as well as their health service usage are complicated issues, generally involving psychological, sociological, and biological considerations (Smith et al., 2006). Similar 
assessments have been reported elsewhere (Gerald \& Ogwuche, 2014; Sullivan et al., 2015). Another school of thought on these issues puts forward that the current health system is generally not well-tailored to meet the ever-changing health needs of men (James Smith et al., 2006; Sullivan et al., 2015). A more recent literature review by Parent et al concluded similar findings (Parent, Hammer, Bradstreet, Schwartz, \& Jobe, 2018).

Cottone, Drucker, and Javier found that, generally, women are more likely to progress beyond the original intake evaluation and complete three months of therapy (Cottone, Drucker, \& Javier, 2002). On the other hand, the findings also noted that men were highly likely to leave therapy after the first intake assessment. A similar study carried out by Doherty and Kartalova-O'Doherty demonstrated gender differences in the models of predictors between women and men, with more factors affecting attendance at the general practitioner stage for men in comparison to women (Doherty \& Kartalova-O'Doherty, 2010). The findings of the study offered the suggestion that a "gender-sensitive approach" ought to be used during the development of mental health policies, mental health promotion, and prevention mechanisms.

\section{Health Education Programs to Improve Men'S Engagement in Healthcare Services}

According to Springer et al., HEPs play a role in building skills, knowledge, and positive attitudes of individuals relating to health (Springer, Evans, Ortuño, Salvo, \& Varela Arevalo, 2017). This conclusion is similar to that of a study conducted by Coe and de Beyer, who argue that HEPs provide individuals with more information concerning mental, physical, emotional, and social health, besides playing a key role in motivating individuals to not only improve, but also maintain their health, prevent disease, and reduce risky behaviors (Coe \& de Beyer, 2014).

As Pantoja et al notes, one of the main functions of a health system entails ensuring effective implementation of different kinds of interventions, with the sole aim of improving health; however, coverage of essential health interventions has generally remained very low in low-income countries (Pantoja et al., 2017). Challenges that hinder this were shown in a study by Rabbani et al., including economic instability and limited capacity for equitable growth (Rabbani et al., 2016). Additionally, an earlier systematic review carried out by Robertson et al. pointed out that inspiring men to successfully use (preventative) health services is regarded as one of the most effective strategies to improve their health (Robertson, Douglas, Ludbrook, Reid, \& van Teijlingen, 2008). A 2017 scoping review by Seaton et al. reported similar findings (Seaton et al., 2017).

\subsection{Gender-Specific Strategies}

In Ireland, the men's health has become a priority. A qualitative study done by Lefkowich, Richardson, and Robertson noted that, despite the fact that various measures have been put into place to prioritize men's health as a matter of national importance, there are still concerns regarding the high level of male non-engagement with various health services (Lefkowich, Richardson, \& Robertson, 2017). This research provided additional understanding into the established measures, which were put into place to ensure that the existing gap between men and health services is reduced. The study outcomes noted that gender-specific strategies, in particular those which are linked to community engagement, are essential in the creation of health programs that promote the health of men and encourage men to participate in a safe and comfortable manner (Lefkowich et al., 2017). Additionally, the findings of this research noted that men ought to be included in every component of the planning steps, as this would be highly beneficial in ensuring that the proposed programs are easily accessible and acceptable to men.

\subsection{Evidence-Based Health Promotion Programs}

A study showed evidence-based health promotion programs are highly effective when it comes to minimizing health risks and healthcare costs among older adults (Anderson, Seff, Batra, Bhatt, \& Palmer, 2016). The authors noted that very few men consistently take part in such programs. The study indicated that approximately $78 \%$ of respondents were in agreement that the perception of various exercise programs as feminine was a key challenge. At the same time, over $90 \%$ of the respondents were of the opinion that program advertisements featuring men are capable of significantly increasing the men's participation levels (Anderson et al., 2016). From the research findings, it can be noted that health promotion programs, as well as recruiting strategies, should be custom-made to the unique requirements and preferences of older men in order to ensure improvement in their levels of participation.

\subsection{Improving Awareness of Health Behaviors}

A study carried out by Mellor, Connaughton, McCabe, and Tatangelo evaluated a new HEP mainly aimed at improving mental and physical health among middle-aged men. The study strived to ensure that there were improvements in the levels of awareness of health behaviors, like exercise and diet, while also on focusing on positive body image messages, coping skills, and self-efficacy. As per the study findings, the program was highly 
effective in generating improvements in the various adaptive coping strategies and body fat percentage at follow-up. It noted that such kinds of HEPs are highly effective (Mellor, Connaughton, McCabe, \& Tatangelo, 2017). In addition, Gavarkovs, Burke, and Petrella also strived to explore some of the main ways through which men can engage in chronic disease prevention and disease management programs. The scoping review noted that program-specific factors which were attractive to men and which encouraged them to take part in interventions included a group component with like-minded men, the application of humour in the provision of health information, the inclusion of nutrition alongside physical activity elements, and the presence of some kind of competition (Gavarkovs, Burke, \& Petrella, 2016).

\subsection{Health Promotion Policies}

In a study by Östlin et al., it was observed that highly effective health promotion policies and programs focused on joint commitment and a multi-sectoral approach; they were also evidence-oriented and took gender dimensions into account (Östlin, Eckermann, Mishra, Nkowane, \& Wallstam, 2006).

\subsection{Acceptability of HIV Self-Testing (HIVST) Interventions Among Men}

According to Johnson et al., HIVST is the process through which an individual carries out a rapid HIV diagnostic test and reads the result privately (Johnson et al., 2014). This new approach has received wide acceptance and has been widely adopted due to its cost-effectiveness. At the same time, it has empowered individuals who might not otherwise go for testing. Van Rooyen et al. also noted that HIVST is capable of increasing the incidence of HIV testing throughout populations within sub-Saharan Africa, which have not yet been tested (van Rooyen et al., 2015). However, it is generally unclear to what degree HIVST would receive support from stakeholders, the kind of policy frameworks which must be put into place, and the manner in which variation between contexts may influence the preparedness of any one country when considering scale-up of the intervention. Van Rooyen et al. also noted that although there is a progressively positive global policy environment concerning HIVST, numerous social and implementation challenges limit the potential for scale-up (van Rooyen et al., 2015). In a different scoping study, the findings indicated that implementation of numerous HIV testing models took place in sub-Saharan Africa (SSA), with most of them aiming to improve access to HIV testing (Harichund \& Moshabela, 2018); however, uptake generally remained very poor. The findings of the review discussed 11 pieces of research at the time of the scoping study, showing variable acceptability $(22.3 \%-94 \%)$ of HIVST. In another study carried out by Ngure et al. concerning the feasibility and acceptability of HIVST among pre-exposure prophylaxis users in Kenya, it was noted that HIVST was widely accepted and could thus be a highly effective strategy of permitting routine HIV testing between pre-exposure prophylaxis (PrEP) refills (Ngure et al., 2017).

Vera, Soni, and Pollard et al. also sought to explore the acceptability and feasibility of employing digital vending machines for delivering HIVST to men having sex with men. The study noted that technology-based approaches for the dissemination of HIVST were capable of increasing access to HIV testing within key populations (Vera et al., 2019). The study sought to assess the acceptability and feasibility of using vending machines (VMs) within a community setting for HIVST distribution to sexually active men (Vera et al., 2019).

A study carried out in South Africa aimed to assess the acceptability of HIVST among women and men in KwaZulu-Natal. The authors stated that HIVST has gained considerable attention as a complement for HIV testing because it ensures that many hindrances associated with current HIV-testing methods are overcome (Harichund, Moshabela, Kunene, \& Abdool Karim, 2019). The study findings noted that HIVST was acceptable among a number of the participants, with acceptability being higher for the women. It was also shown that a number of the men preferred HIVST because of the convenience and efficiency that the method brings. Women generally favoured HIVST because of its ability to offer autonomy, as well as empowerment (Harichund et al., 2019).

Kelvin et al. also carried out a study with the aim of exploring whether self-administered, at-home oral HIV testing was capable of effectively addressing some of the key hindrances to HIV testing in South Africa at the social, individual, and interpersonal levels. It further suggested that this testing modality might be more suitable in comparison to the present clinic-oriented testing system. The study also noted that self-testing is generally not ideal for all individuals and does not make clinic-oriented HCT services obsolete; rather, it provides individuals with different HIV testing choices (Kelvin et al., 2016). In a systematic review carried out by Krause et al., the authors noted that the uptake of HIV testing and HIV counseling services has remained very low in at-risk groups globally, pointing out that fear of stigmatization, discrimination, and breach of confidentiality contributes to low service utilization among at-risk groups (Krause, Subklew-Sehume, Kenyon, \& Colebunders, 2013). The authors thus evaluated the acceptability of HIVST as well as some of the key benefits and various challenges associated with the introduction of HIVST. The research findings illustrated that HIVST is generally an acceptable testing alternative for at-risk groups. They further noted that clients value the privacy and the confidentiality associated 
with HIVST; some of the main challenges included counseling concerns (Krause et al., 2013).

Dodds et al. also carried out a study with the aim of investigating the acceptability of HIV self-sampling kits among individuals of black African ethnicity within the United Kingdom. The findings revealed three valuable aspects of the targeted HIV self-sampling kit intervention (Dodds et al., 2018), including the use of settings and technologies which increase choice and autonomy, targeted offers of HIV testing which ensure privacy and do not exacerbate HIV stigma, and making sure that the kits are perceived as reliable and simple (Dodds et al., 2018).

The findings of Volk et al. noted very high feasibility, acceptability, and interest in a blood-based assay HIVST among at-risk men who have sex with men (MSM) in Brazil and Peru (Volk et al., 2016). The research noted that access to low-cost, affordable HIVST provides the potential to increase testing frequency and reach MSM who do not currently have access to HIV-testing services. The study noted that continuous efforts are required to confirm the level of accuracy of the self-testing method outside of the trial setting and to make sure that people with positive test results are connected to healthcare services for confirmatory testing and treatment (Volk et al., 2016).

\section{Discussion}

This review presented literature evidence on male HSB, HEPs for men's engagement in health services, and evidence on men's acceptability of HIVST interventions. An understanding of HSB is needed to help tailor HEPs accordingly. When it comes to HSB in men, further research through the use of heterogeneous samples is needed so as to further comprehend the triggers and barriers that are linked to the decision-making process regarding help-seeking behavior among men. At the same time, based on the findings of our review, there is need for future theory building and research which accounts for variation at the intersection of race/ethnicity and specific predictors of help-seeking behavior among men. We note that research around HIVST in SSA is still at its infancy stage; additional implementation research and interventions are needed in order to generate improvement in the acceptability of HIVST among different study populations.

We propose a framework to help improve men's engagement in health services in Figure 2. The four pillars involve exploring evidence-based health promotion programs that are driven by an understanding of HSB. The design of such programs should be gender-specific to target men. Finally, public awareness and improved capacity of healthcare providers is critical for the improvement of men's engagement in health services.

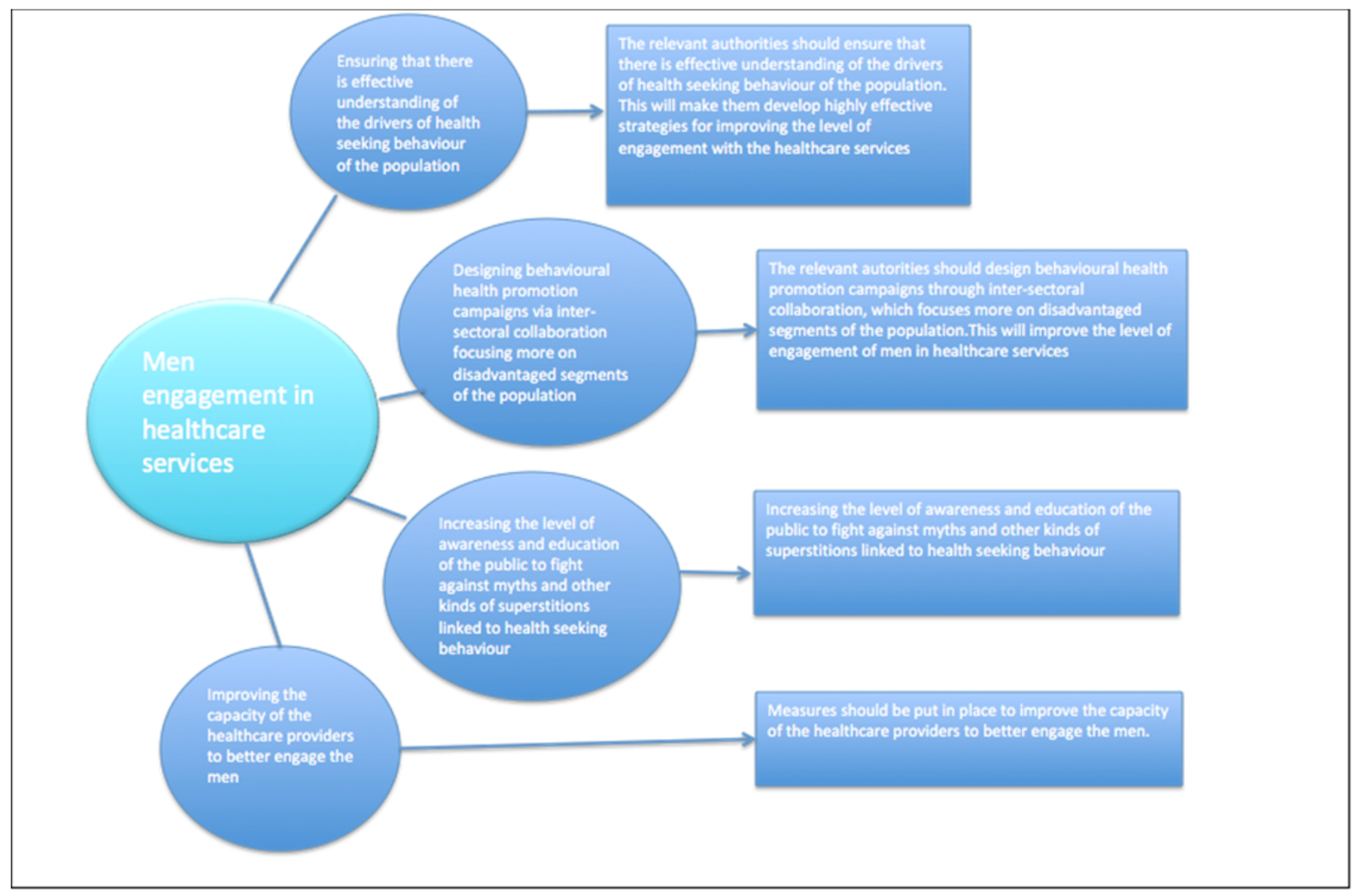

Figure 2. A proposed framework to help improve men engagement in healthcare services in LMICs (Dzinamarira T and Thompson- Mashamba T. P., 2019) 
In this paper, we reviewed variables predicting healthcare-seeking behavior, which can be useful in tailoring interventions. Based on the review, it can be noted that different kinds of factors affect men and women when requesting help for various health problems. As a result, there is a need for different kinds of policies to be developed with these kinds of disparities in mind in order to ensure that proper, gender-specific prevention and treatment approaches are used. At the same time, policy-makers need to comprehend the drivers of health-seeking behaviors of a population within increasingly pluralistic healthcare systems. More intensive effort is needed to design behavioral health promotion campaigns via intersectoral collaboration, with a heavier focus on disadvantaged segments of the population. Serious efforts are also needed to increase public awareness and education in order to fight against myths and superstitions that are linked to health-seeking behavior. Finally, there is need for various kinds of measures to be put in place to improve the capacity of healthcare providers to better engage men. There should also be proper policies in place and an emphasis on program development to improve engagement in men.

Although cost has an impact on the acceptability of HIVST among men, the price of HIVST kits has not been extensively assessed across the globe. This aspect requires more research to minimize the economic burden on at-risk individuals and also to limit the cost implications for governments and healthcare providers. Further, our review revealed that linkage to counseling, treatment, and care services remains a major challenge, and this should not be ignored.

\section{Conclusion}

Our review revealed that the main factors which contribute to male aversion to healthcare are multifaceted and require equally complex interventions. In order to improve the level of engagement of men in healthcare, this study has provided a framework which can be adopted. Ensuring effective understanding of the drivers of HSB in men is a critical first step. Designing behavioral health promotion campaigns via intersectoral collaborations focusing more on men, with the aim of increasing the level of awareness and education of the public to fight against myths and other kinds of superstitions linked to HSB, is also necessary. Further, improving the capacity of healthcare providers to better engage men is needed.

We concluded that HEPs might also be highly effective in addressing poor HSB among key populations, including men, and may improve uptake of HTS. Finally, our review revealed that research around HIVST in SSA is still at its infancy stage, and additional implementation research and interventions are needed in order to improve acceptability of HIVST among men.

\section{Ethical Approval}

Not applicable.

\section{Funding}

No funding was received for this study.

\section{Author Information}

Tafadzwa Dzinamarira is a Doctor of Philosophy (Medicine) candidate at the Department of Public Health Medicine, School of Nursing and Public Health, University of KwaZulu-Natal under the supervision of Dr. Tivani P. Mashamba-Thompson.

\section{Competing Interests Statement}

The authors declare that they have no competing interests, which may have inappropriately influenced them in writing this article.

\section{Aknowledgements}

This study was supported by the CIHR Canadian HIV Trials Network (CTN 222). Dr. Tivani P. Mashamba-Thompson is supported by CTN Postdoctoral Fellowship Award.

\section{References}

Adegoke, A. A. (2010). Correlates of health behavior practices among literate adults of south west, Nigeria (Vol.10, No. 2, 26).

Anderson, C., Seff, L. R., Batra, A., Bhatt, C., \& Palmer, R. C. (2016). Recruiting and engaging older men in evidence-based health promotion programs: Perspectives on barriers and strategies. Journal of aging research, 2016. https://doi.org/10.1155/2016/8981435

Biya, O., Gidado, S., Abraham, A., Waziri, N., Nguku, P., Nsubuga, P., . . Sabitu, K. (2014). Knowledge, 
care-seeking behavior, and factors associated with patient delay among newly-diagnosed pulmonary tuberculosis patients, Federal Capital Territory, Nigeria, 2010. The Pan African Medical Journal, 18(Suppl 1). https://doi.org/10.11604/pamj.supp.2014.18.1.4166

Choko, A. T., MacPherson, P., Webb, E. L., Willey, B. A., Feasy, H., Sambakunsi, R., . . Hayes, R. J. P. m. (2015). Uptake, accuracy, safety, and linkage into care over two years of promoting annual self-testing for HIV in Blantyre, Malawi: a community-based prospective study. PLOS Medicine, 12(9), e1001873. https://doi.org/10.1371/journal.pmed.1001873

Coe, G., \& de Beyer, J. (2014). The imperative for health promotion in universal health coverage. Global Health: Science and Practice, 2(1), 10-22. https://doi.org/10.9745/GHSP-D-13-00164

Conserve, D. F., Muessig, K. E., Maboko, L. L., Shirima, S., Kilonzo, M. N., Maman, S., \& Kajula, L. J. P. o. (2018). Mate Yako Afya Yako: Formative research to develop the Tanzania HIV self-testing education and promotion (Tanzania STEP) project for men. PLOS one, 13(8), e0202521. https://doi.org/10.1371/journal.pone.0202521

Cottone, J. G., Drucker, P., \& Javier, R. A. (2002). Gender differences in psychotherapy dyads: Changes in psychological symptoms and responsiveness to treatment during 3 months of therapy. Psychotherapy: Theory, Research, Practice, Training, 39(4), 297. https://doi.org/10.1037/0033-3204.39.4.297

Dodds, C., Mugweni, E., Phillips, G., Park, C., Young, I., Fakoya, F., . . Chwaula, J. (2018). Acceptability of HIV self-sampling kits (TINY vial) among people of black African ethnicity in the UK: a qualitative study. BMC Public Health, 18(1), 499. https://doi.org/10.1186/s12889-018-5775-0

Doherty, D. T., \& Kartalova-O'Doherty, Y. (2010). Gender and self-reported mental health problems: predictors of help seeking from a general practitioner. British journal of health psychology, 15(1), 213-228. https://doi.org/10.1348/135910709X457423

Galdas, P. M., Cheater, F., \& Marshall, P. (2005). Men and health help-seeking behaviour: literature review. Journal of Advanced Nursing, 49(6), 616-623. https://doi.org/10.1111/j.1365-2648.2004.03331.x

Gavarkovs, A. G., Burke, S. M., \& Petrella, R. J. (2016). Engaging men in chronic disease prevention and management programs: a scoping review. American journal of men's health, 10(6), NP145-NP154. https://doi.org/10.1177/1557988315587549

Gerald, E. I. E. U., \& Ogwuche, C. H. E. (2014). Educational level, sex and church affiliation on health seeking behaviour among parishioners in Makurdi metropolis of Benue state. Journal of Educational Policy and Entrepreneurial Research, 1(2), 311-316.

Gichangi, A., Wambua, J., Gohole, A., Mutwiwa, S., Njogu, R., \& Bazant, E. (2016). Provision of oral HIV self-test kits triples uptake of HIV testing among male partners of antenatal care clients: results of a randomized trial in Kenya. Paper presented at the 21st International AIDS Conference.

Harichund, C., \& Moshabela, M. (2018). Acceptability of HIV self-testing in sub-Saharan Africa: scoping study. AIDS and Behavior, 22(2), 560-568. https://doi.org/10.1007/s10461-017-1848-9

Harichund, C., Moshabela, M., Kunene, P., \& Abdool Karim, Q. (2019). Acceptability of HIV self-testing among men and women in KwaZulu-Natal, South Africa. AIDS care, 31(2), 186-192. https://doi.org/10.1080/09540121.2018.1503638

Hubley, J. (1980). Community development and health education. Journal of the Institute of Health Education, 18(4), 113-120. https://doi.org/10.1080/03073289.1980.10805488

Johnson, C., Baggaley, R., Forsythe, S., Van Rooyen, H., Ford, N., Mavedzenge, S. N., . . Taegtmeyer, M. (2014). Realizing the potential for HIV self-testing. AIDS and Behavior, 18(4), 391-395. https://doi.org/10.1007/s10461-014-0832-x

Justman, J., Hoos, D., Kalton, G., Nyirenda, R., Moyo, C., \& Mugurungi, O. (2017). Real progress in the HIV epidemic: PHIA findings from Zimbabwe, Malawi, and Zambia. Paper presented at the Conference on Retroviruses and Opportunistic Infections.

Kakkar, R., Kandpal, S., Negi, K., \& Kumar, S. (2013). To study health seeking behavior of population catered by rural health training centre, Rajeev Nagar. Indian J Prev Soc Med, 44, 3-4.

Kelvin, E. A., Cheruvillil, S., Christian, S., Mantell, J. E., Milford, C., Rambally-Greener, L., . . Smit, J. A. (2016). Choice in HIV testing: the acceptability and anticipated use of a self-administered at-home oral HIV test 
among South Africans. African Journal of AIDS Research, 15(2), 99-108. https://doi.org/10.2989/16085906.2016.1189442

Kojima, N., \& Klausner, J. D. (2018). Accelerating epidemic control: the role of HIV self-testing. The lancet HIV. https://doi.org/10.1016/S2352-3018(18)30063-8

Krause, J., Subklew-Sehume, F., Kenyon, C., \& Colebunders, R. (2013). Acceptability of HIV self-testing: a systematic literature review. BMC Public Health, 13(1), 735. https://doi.org/10.1186/1471-2458-13-735

Kumar, S., \& Preetha, G. (2012). Health promotion: an effective tool for global health. Indian journal of community medicine: official publication of Indian Association of Preventive \& Social Medicine, 37(1), 5. https://doi.org/10.4103/0970-0218.94009

Lefkowich, M., Richardson, N., \& Robertson, S. (2017). "If we want to get men in, then we need to ask men what they want": pathways to effective health programing for men. American journal of men's health, 11(5), 1512-1524. https://doi.org/10.1177/1557988315617825

Lippman, S. A., Lane, T., Rabede, O., Gilmore, H., Chen, Y.-H., Mlotshwa, N., . . McIntyre, J. A. J. J. J. o. A. I. D. S. (2018). High Acceptability and Increased HIV-Testing Frequency After Introduction of HIV Self-Testing and Network Distribution Among South African. MSM, 77(3), 279-287. https://doi.org/10.1097/QAI.0000000000001601

Masters, S. H., Agot, K., Obonyo, B., Mavedzenge, S. N., Maman, S., \& Thirumurthy, H. J. (2016). Promoting partner testing and couples testing through secondary distribution of HIV self-tests: a randomized clinical trial. PLoS medicine, 13(11), e1002166. https://doi.org/10.1371/journal.pmed.1002166

Mellor, D., Connaughton, C., McCabe, M. P., \& Tatangelo, G. (2017). Better with age: A health promotion program for men at midlife. Psychology of Men \& Masculinity, 18(1), 40. https://doi.org/10.1037/men0000037

Musoke, D., Boynton, P., Butler, C., \& Musoke, M. B. (2014). Health seeking behaviour and challenges in utilising health facilities in Wakiso district, Uganda. African health sciences, 14(4), 1046-1055. https://doi.org/10.4314/ahs.v14i4.36

Ngure, K., Heffron, R., Mugo, N., Thomson, K. A., Irungu, E., Njuguna, N., . . Baeten, J. M. (2017). Feasibility and acceptability of HIV self-testing among pre-exposure prophylaxis users in Kenya. Journal of the International AIDS Society, 20(1), 21234. https://doi.org/10.7448/IAS.20.1.21234

Nzama, N. (2013). Masculinity and men's health seeking behaviours amongst Black/African men: the case of Durban, KwaZulu-Natal, South Africa.

Olenja, J. (2003). Editorial Health seeking behaviour in context. East African medical journal, 80(2), 61-62. https://doi.org/10.4314/eamj.v80i2.868

Omotoso, D. (2010). Health seeking behaviour among the rural dwellers in Ekiti State, Nigeria. African Research Review, 4(2). https://doi.org/10.4314/afrrev.v4i2.58296

Östlin, P., Eckermann, E., Mishra, U. S., Nkowane, M., \& Wallstam, E. (2006). Gender and health promotion: A multisectoral policy approach. Health promotion international, 21(suppl_1), 25-35. https://doi.org/10.1093/heapro/dal048

Pantoja, T., Opiyo, N., Lewin, S., Paulsen, E., Ciapponi, A., Wiysonge, C. S., . . . Dudley, L. (2017). Implementation strategies for health systems in low-income countries: an overview of systematic reviews. Cochrane database of systematic reviews, (9). https://doi.org/10.1002/14651858.CD011086.pub2

Parent, M. C., Hammer, J. H., Bradstreet, T. C., Schwartz, E. N., \& Jobe, T. (2018). Men's mental health help-seeking behaviors: An intersectional analysis. American journal of men's health, 12(1), 64-73. https://doi.org/10.1177/1557988315625776

Rabbani, F., Shipton, L., White, F., Nuwayhid, I., London, L., Ghaffar, A., . . Islam, A. (2016). Schools of public health in low and middle-income countries: an imperative investment for improving the health of populations? BMC Public Health, 16(1), 941. https://doi.org/10.1186/s12889-016-3616-6

Robertson, L. M., Douglas, F., Ludbrook, A., Reid, G., \& van Teijlingen, E. (2008). What works with men? A systematic review of health promoting interventions targeting men. BMC health services research, $8(1), 141$. https://doi.org/10.1186/1472-6963-8-141

Seaton, C. L., Bottorff, J. L., Jones-Bricker, M., Oliffe, J. L., DeLeenheer, D., \& Medhurst, K. (2017). Men's 
mental health promotion interventions: a scoping review. American journal of men's health, 11(6), 1823-1837. https://doi.org/10.1177/1557988317728353

Senbeto, M., Tadesse, S., Tadesse, T., \& Melesse, T. (2013). Appropriate health-seeking behavior and associated factors among people who had cough for at least two weeks in northwest Ethiopia: a population-based cross-sectional study. BMC Public Health, 13(1), 1222. https://doi.org/10.1186/1471-2458-13-1222

Shaikh, B. T., \& Hatcher, J. (2004). Health seeking behaviour and health service utilization in Pakistan: challenging the policy makers. Journal of public health, 27(1), 49-54. https://doi.org/10.1093/pubmed/fdh207

Skovdal, M., Campbell, C., Madanhire, C., Mupambireyi, Z., Nyamukapa, C., \& Gregson, S. (2011). Masculinity as a barrier to men's use of HIV services in Zimbabwe. Globalization and health, 7(1), 13. https://doi.org/10.1186/1744-8603-7-13

Smith, J., Braunack-Mayer, A., \& Wittert, G. (2006). What do we know about men's help-seeking and health service use? Medical Journal of Australia, 3.

Springer, A. E., Evans, A. E., Ortuño, J., Salvo, D., \& Varela Arevalo, M. T. (2017). Health by design: interweaving health promotion into environments and settings. Frontiers in public health, 5, 268. https://doi.org/10.3389/fpubh.2017.00268

Sullivan, L., Camic, P. M., \& Brown, J. S. (2015). Masculinity, alexithymia, and fear of intimacy as predictors of UK men's attitudes towards seeking professional psychological help. British journal of health psychology, 20(1), 194-211. https://doi.org/10.1111/bjhp.12089

Thompson, A. E., Anisimowicz, Y., Miedema, B., Hogg, W., Wodchis, W. P., \& Aubrey-Bassler, K. (2016). The influence of gender and other patient characteristics on health care-seeking behaviour: a QUALICOPC study. BMC Family Practice, 17(1), 38. https://doi.org/10.1186/s12875-016-0440-0

UNAIDS. (2014). 90-90-90: an ambitious treatment target to help end the AIDS epidemic. Retrieved from Geneva, Switzerland:

UNAIDS. (2017a). Blind spot - Reaching out to men and boys addressing a blind spot in the response to HIV.

UNAIDS. (2017b). Ending AIDS: Progress towards the 90-90-90 targets. Geneva, Switzerland:

Vanessa, B. (2013). A review of the literature: men's health-seeking behaviour and use of the internet. Retrieved from www.menshealthforum.org.uk/sites/default/files/pdf/mens_health_literature_review_dec2013_ final.pdf

van Rooyen, H., Tulloch, O., Mukoma, W., Makusha, T., Chepuka, L., Knight, L. C., . . Chirwa, E. (2015). What are the constraints and opportunities for HIVST scale-up in Africa? Evidence from Kenya, Malawi and South Africa. Journal of the International AIDS Society, 18(1), 19445. https://doi.org/10.7448/IAS.18.1.19445

Vera, J. H., Soni, S., Pollard, A., Llewellyn, C., Peralta, C., Rodriguez, L., \& Dean, G. (2019). Acceptability and feasibility of using digital vending machines to deliver HIV self-tests to men who have sex with men. Sexually transmitted infections, sextrans-2018-053857. https://doi.org/10.1136/sextrans-2018-053857

Volk, J. E., Lippman, S. A., Grinsztejn, B., Lama, J. R., Fernandes, N. M., Gonzales, P., . . Buchbinder, S. (2016). Acceptability and feasibility of HIV self-testing among men who have sex with men in Peru and Brazil. International journal of STD \& AIDS, 27(7), 531-536. https://doi.org/10.1177/0956462415586676

World Health Orgnization [WHO]. (2016). Guidelines on HIV self-testing and partner notification: supplement to consolidated guidelines on HIV testing services (9241549866).

\section{Copyrights}

Copyright for this article is retained by the author(s), with first publication rights granted to the journal.

This is an open-access article distributed under the terms and conditions of the Creative Commons Attribution license (http://creativecommons.org/licenses/by/4.0/). 